\title{
СООТНОШЕНИЕ ОБЯЗАТЕЛЬСТВ РОССИИ В СВЯЗИ С ПРИСОЕДИНЕНИЕМ К ВТО И ЗАКОНОДАТЕЛЬСТВА РФ В СФЕРЕ МЕЖДУНАРОДНОЙ ТОРГОВЛИ ТОВАРАМИ
}

\section{THE RATIO OF RUSSIA'S OBLIGATIONS IN CONNECTION WITH ACCESSION TO THE WTO AND THE LEGISLATION OF THE RUSSIAN FEDERATION IN THE FIELD OF INTERNATIONAL TRADE IN GOODS \\ N. Pokrovskaia}

Summary: The main purpose of this research was to study Russia's obligations in connection with accession to the WTO and the legislation of the Russian Federation in the field of international trade in goods. It was noted that obeying the WTO rules, based on the «Protocol on Russia's accession to the Treaty establishing the WT0», Russia consolidates its transition to a market economy. It is important to note that this step links Russia with the principle of non-discrimination between WTO members, which limits its ability to use its economic potential for geopolitical purposes. In exchange for restrictions on its economic sovereignty, Russia received the right not to be discriminated against by other WTO members and to receive from them a trade regime based on WTO rules. It is concluded that Russia's membership in the WTO can serve as a tool helping Russia to become stronger, more competitive both domestically and internationally, and more influential in the international arena, not only economically, but also politically.

Keywords: private international law, WTO law, accession to the WTO, goods, international trade in goods, tariff policy.

\author{
Покровская Наталья Владимировна \\ Соискатель, Казанский (Приволжский) \\ федеральный университет \\ nataliavladimirovnapokrovskaia@gmail.com
}

Аннотация: Основной целью настоящего исследования выступило изучение обязательств России в связи с присоединением к ВТО и законодательства РФ в сфере международной торговли товарами. Отмечено, что, подчиняясь правилам ВТ0, на основе «Протокола о присоединении России к Договору 06 учреждении ВТ0», Россия закрепляет свой переход к рыночной экономике. Этот шаг связывает Россию с принципом недискриминации между членами ВТО, ограничивающим ее возможности использовать свой экономический потенциал в геополитических целях. В обмен на ограничения своего экономического суверенитета Россия получила право не подвергаться дискриминации со стороны других членов ВТО и получать от них торговый режим, основанный на правилах ВТО. Сделан вывод, что членство России в ВТ0 может служить инструментом, помогающим России стать сильнее, конкурентоспособнее как на национальном, так и на международном уровне и более влиятельной на международной арене не только экономически, но и политически.

Ключевые слова: международное частное право, право ВТ0, присоединение к BTO, товары, международная торговля товарами, тарифная политика.

после столетия противостояния на мировой арене.

Как известно, международная торговля - это обмен товарами и услугами. При ее осуществлении экспорт позволяет стимулировать рост экономики и создавать рабочие места. Импорт увеличивает ассортимент продукции на внутреннем рынке и позволяет снижать цены, что выгодно потребителям. С другой стороны, конкурентное давление, оказываемое импортом, может вывести отечественных производителей из бизнеса, особенно если они плохо подготовлены, а их продукция не может конкурировать по качеству и цене. Рабочие места исчезают, а внутреннее производство падает. В крайнем случае стабильность отечественной экономики может оказаться под угрозой. При этом снижение торговых барьеров, повышение правовой определенности во всем мире и снижение транспортных издержек означают, что глобальные компании теперь могут производить товары там, где это дешевле - а это 
часто происходит там, где зарплаты ниже, то есть в развивающихся странах. В результате на развивающиеся государства сейчас приходится значительный объем мировой торговли, например, на государства - члены БРИКС (только на Бразилию, Россию, Индию и Китай приходится около 20\% мировой торговли товарами).

В этой связи основная цель ВТО состоит в том, чтобы управлять примерно 60 соглашениями и отдельными обязательствами, принятыми ее членами в рамках ГАТТ (для торговли товарами) [2]. Вступив в ВТО, Россия продемонстрировала свою готовность принять установленные правила международной торговли товарами и соблюдать их. Членство в ВТО обязывает Россию соблюдать основополагающие принципы в торговле с другими членами [3], предполагая:

- режим наибольшего благоприятствования (РНБ): импорт товаров и услуг из одного государствачлена будет рассматриваться не менее благоприятно, чем импорт товаров и услуг из любого другого государства-члена ВТО. РНБ должен быть безусловным. На практике это означает, что в большинстве случаев Россия не может применять более высокий импортный тариф к товару из одного государства-члена, чем он применяется к аналогичным товарам из любой другого государства-члена ВТО.

- национальный режим: импорт товаров и услуг предполагает не менее благоприятный режим, чем аналогичные товары и услуги, произведенные внутри государства. В практическом плане это означает что государство не может дискриминировать импорт при применении законов и правил, таких как правила обеспечения безопасности, защиты потребителей или окружающей среды.

- прозрачность: нормативные правовые акты, влияющие на внешнюю торговлю и инвестиции, должны быть опубликованы и доступны для всех желающих. Процедуры реализации законов и нормативных актов должны быть открытыми.

- снижение торговых барьеров путем переговоров: с момента создания ГАТТ его члены проводят постоянные переговоры по снижению торговых барьеров. Сначала эти переговоры были сосредоточены на снижении тарифов. Но со временем эти раунды расширили охват ГАТТ/ВТО, включив в него нетарифные барьеры, такие как дискриминационная практика государственных закупок, дискриминационные стандарты и искажающие торговлю государственные субсидии. В частности, Уругвайский раунд привел к наиболее масштабному расширению правил, впервые охватывающему торговлю сельскохозяйственной продукцией и услугами, а также государственную политику и практику, касающиеся защиты прав интеллектуальной собственности и иностранных инвестиций. инвестиционные правила, влияющие на торговлю.

- зависимость от тарифов: в целях содействия предсказуемости и открытости торговли ВТО требует от России использовать тарифы и избегать использования квот или других нетарифных мер при ограничении импорта в законных целях, например в отношении вредного импорта. В рамках своей функции по администрированию правил, установленных в соответствии с соглашениями, ВТО обеспечивает механизм урегулирования споров между членами, если спор связан с предполагаемыми нарушениями соглашений ВТО. Кроме того, торговый режим каждого члена постоянно пересматривается и Секретариат ВТО время от времени следит за тем, чтобы он соответствовал правилам ВТО.

В целом торговые последствия присоединения России в контексте торговли товарами, консолидированные в соответствующем Докладе рабочей группы, сводятся к следующему: несмотря на то, что средние тарифные ставки снижались еще до вступления государства в ВТО, российская протекционистская политика в отношении некоторых значимых товаров (включая автомобили и сигареты) подлежала пересмотру. Кроме того, квоты на сельскохозяйственную продукцию, а также протекционистское использование санитарного и фитосанитарного контроля должны быть отменены - правила ВТО предписывают использование международных стандартов для СФС-контроля и требуют от членов обеспечить надежную научную основу для любых более строгих мер.

Следовательно, присоединение Российской Федерации является важным шагом в процессе универсализации международной торговли. Подчиняясь правилам BTO, на основе «Протокола о присоединении России к Договору об учреждении ВТО», Россия закрепляет свой переход к рыночной экономике. Важно отметить, что этот шаг связывает Россию с принципом недискриминации между членами ВТО, ограничивающим ее возможности использовать свой экономический потенциал в геополитических целях. В обмен на ограничения своего экономического суверенитета Россия получила право не подвергаться дискриминации со стороны других членов ВТО и получать от них торговый режим, основанный на правилах ВТО. Что еще более важно, с присоединением Россия получила право голоса в форуме, который в настоящее время доминирует в регулировании вопросов мировой торговли.

Противниками вступления России в ВТО утверждалось, что членство в ВТО было бы излишним и даже вредным для России. Ее экспорт состоит в основном из нефти, газа и сырья, которые облагаются обоснованными налогами и не подвергаются дискриминации; ее вы- 
сокотехнологичный экспорт сосредоточен в оборонной сфере, которая не подпадает под действие правил ВТО. Поэтому присоединение нанесло бы ущерб, т.к. российская промышленность в значительной степени неконкурентоспособна и не предоставляет взамен никаких существенных выгод.

Однако эта позиция упускала два фундаментальных момента. Во-первых, либеральная экономика утверждает, что снижение торговых барьеров не только повышает национальное благосостояние, но фактически повышает конкурентоспособность в долгосрочной перспективе, в то время как непрерывная защита ведет к увеличению разрыва в производительности между отечественной и зарубежной промышленностью. Во-вторых, интерес России к вступлению в ВТО во многом обусловлен ее стремлением к влиянию в глобальных вопросах, которое она больше не может осуществлять, опираясь исключительно на военную мощь. Это является отражением более глубоких изменений в международных отношениях.

Справедливо было бы сказать, что международная специализация России как производителя нефти, газа и минерального сырья, вполне приемлемая при определенных условиях в краткосрочном плане, еще не переросла в более развитые формы экономической деятельности. Нынешняя торговая политика российского государства не направлена на содействие более глубокой переработке природных ресурсов, что является серьезной проблемой. препятствие для экспансии России на зарубежные рынки. Это также делает страну сильно зависимой от мировых цен на сырье.

В условиях углубления финансового кризиса и падения мировых фондовых индексов нефти и металлов негативные последствия такой политики вполне ощутимы. Как и многие другие государства, экспортирующие сырье, Россия тратит соответствующую выручку на высокотехнологичные машины и оборудование (производимые в основном именно теми странами, которым она продает сырье), что вряд ли можно охарактеризовать как перспективную стратегию с точки зрения долгосрочного экономического развития страны. Неспособность переломить эту тенденцию - один из самых очевидных просчетов в торговой политике России последних лет.

Действительно, товарная структура российского экспорта отражает сырьевую направленность экономики государства. Абсолютным лидером экспорта среди отраслей промышленности является минеральносырьевой сектор, и особенно энергетика, их позиции постоянно укрепляются, а объемы экспорта растут. Однако вторая по величине группа экспортируемых российских товаров - металлы и изделия из них. Хотя многие страны ограничивают доступ российского металлопроката на свои рынки, устанавливая сильные антидемпинговые барьеры, он остается высококонкурентным, даже если его называют «товаром в процессе производства». Также важными статьями российского экспорта являются химическая продукция (в первую очередь минеральные удобрения) и машиностроение (около 50\% всех экспортируемых машин и оборудования идет в страны СНГ).

Тем не менее, анализ последствий вступления в ВТО для осуществления международной торговли указывает как на экономические потери, так и на выгоды. Экономические потери в первую очередь связаны с частичной либерализацией таможенных тарифов. С другой стороны, либерализация тарифов в отдельных отраслях приводит к росту объемов производства. Другие позитивные последствия вступления в ВТО включают улучшение доступа российских экспортеров на внешние рынки и рост объема прямых инвестиций в либерализующиеся секторы товаров.

В целом членство России в ВТО может служить серьезным правовым инструментом, помогающим России стать сильнее, конкурентоспособнее как внутри страны, так и на международном уровне и более влиятельной на международной арене не только экономически, но и политически. Соглашаясь с правилами и положениями ВТО, Россия гарантирует соблюдение протоколов и руководящих принципов ВТО и разрешать многосторонние торговые споры с другими государствами в рамках ВТО, что позволяет обеспечивать эффективную международную торговлю товарами.

\section{ЛИТЕРАТУРА}

1. Федеральный закон «0 ратификации Протокола о присоединении Российской Федерации к Марракешскому соглашению об учреждении Всемирной торговой организации от 15 апреля 1994 г.» от 21.07.2012 N 126-Ф3 (последняя редакция) / КонсультантПлюс (consultant.ru).

2. Генеральное соглашение по тарифам и торговле (ГАTT 1947) URL: http://docs.cntd.ru/document/1901981

3. О Плане мероприятий по приведению законодательства Российской Федерации в соответствие с нормами и правилами Всемирной торговой организации (с изменениями на 21 июня 2002 года), Распоряжение Правительства РФ от 08 августа 2001 года №1054-p (cntd.ru)

4. Решение о принятии Соглашения об учреждении ВТ0 и присоединении к нему от 15.11.1994 // Собрание законодательства РФ. 2012 . № 37 (приложение, ч. V). (T. 2429-2430. 